\title{
Factors affecting the environment of the city of Vladivostok
}

\author{
Botir Giyasov ${ }^{1, *}$ and Ruslan Giyasov ${ }^{2}$ \\ ${ }^{1}$ Moscow State University of Civil Engineering, Yaroslavskoe shosse, 26, Moscow, 129337, Russia
}

\begin{abstract}
The problem of environment degradation in cities due to the development of megalopolises is demanding urgent attention. The rapid growth of modern cities caused by the need to improve the living conditions contributes to the construction of new buildings and structures, the development of transport and engineering networks. As a result, the density of urban environment increases, the congestion of transport networks increases, leading to environmental pollution and aggravating the environmental situation in cities. The article is devoted to the analysis of the environment of major cities in Russia using the example of the city of Vladivostok. The main factors influencing the environmental pollution, which are characteristic only of modern cities, have been identified. The relationship between energy consumption by various branches of the economy and environmental pollution has been established. Using the example of the city of Vladivostok, the analysis of the aerodynamics of the urban space is carried out, and the parameters for changing the wind speed with the changes in the height of the building have been revealed. The role of convective flows in improving the urban environment has been justified. The main reasons aggravating the environment of cities have been found out. These include significant harmful emissions from vehicles and air exchange in urban areas disturbed due to dense buildings, which leads to a high concentration of harmful substances that pollute the city.
\end{abstract}

\section{Introduction}

The importance of urban environmental problems has increased considerably. The growth of pollution caused by industrial emissions and increased transport and engineering networks in cities is in the center of attention of the global community. Modern major cities tend to develop and increase urban construction. This is due to the rapid pace of economic development and urbanization. The intensity of internal and external migration of people to big cities entails an increase in population density, as a result of which the number of modern high-rise buildings and skyscrapers increases. A modern metropolis can be characterized as a living environment, consisting of such environments as the natural environment, the high-tech environment, the transport environment, the environment with dense buildings and developed engineering and transport networks. In the course of urbanization, the development of Russian cities is based on the historical specifics of the

* Corresponding author: dandyr@mail.ru 
growth of population and industries, as well as on changing conditions for the formation of the urban environment [1-3].

Most Russian cities are in unfavorable conditions in terms of energy costs. In addition, the self-healing of natural biological systems in Russian regions is much lower than in regions of warm countries. This leads to the fact that in modern megalopolises with a high population density and intensive economic activity, the environment is significantly affected.

In Russia, about $80 \%$ of the population lives in an urban environment. In cities with more than one million residents, due to the ongoing growth of population, more and more high-rise buildings are being built these days. Russia is determined to increase the turnover of construction in large cities. A clear growth in construction volumes is shown in the graph (Fig. 1) [4].

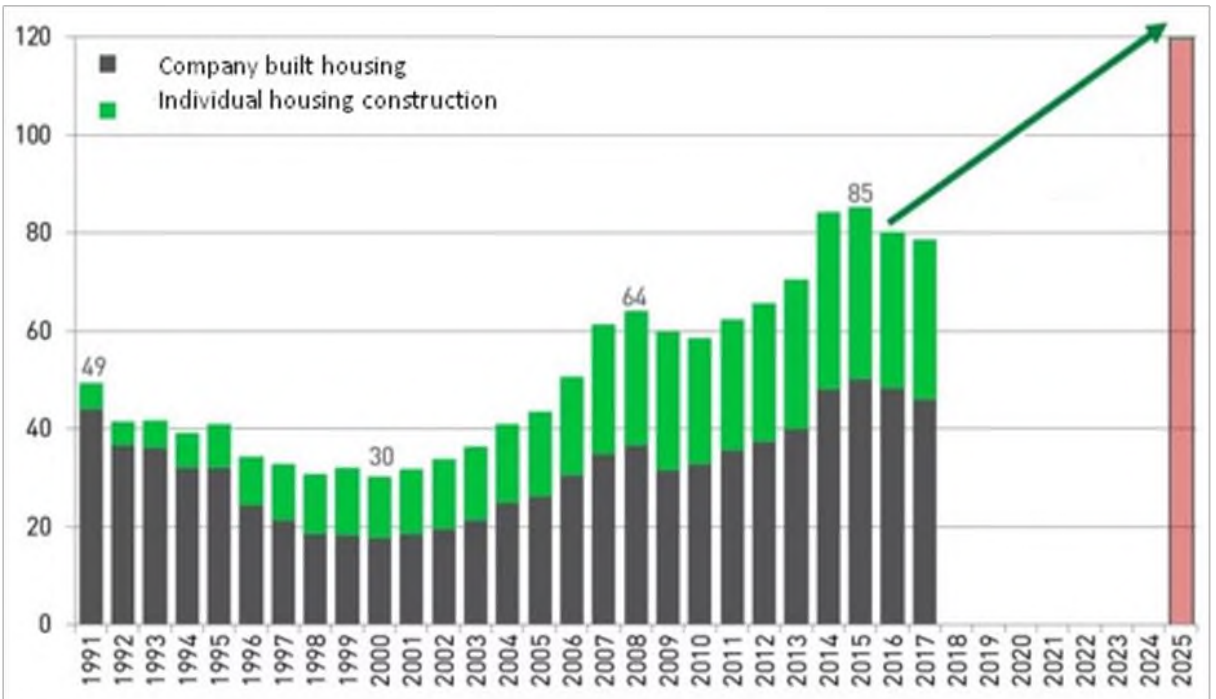

Fig. 1. Growth of urban construction

Obviously, in this regard, the density of urban construction is increasing and the engineering and transport networks are rapidly developing. As a result, in modern cities, the heat-wind conditions are changing, and extensive stable zones with air stagnation are being formed. Such phenomena and factors, characteristic of developed cities, adversely affect the surrounding urban environment and are insufficiently studied.

One of the main negative factors affecting modern cities is air pollution caused by emissions from transport, industry and civil objects. In connection with the intensive development of the urban structure, energy consumption by transport, industry and civilian objects is increasing. The growing population density in cities is causing an increase in urban density. In this regard, the number of vehicles is increasing, which leads to an increase in energy consumption and emissions of harmful substances. Of course, environmental pollution mainly occurs due to the consumption of fuel and energy resources by various sectors of the economy (Fig. 2) [5]. 


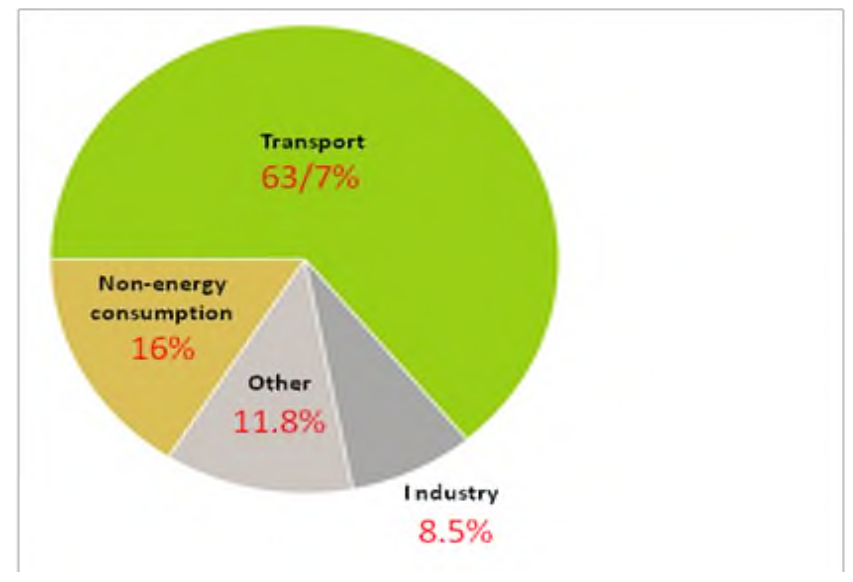

Fig. 2. Consumption of oil products by industry

Such active energy consumption, accompanied by constant emissions, also increases the level of urban pollution. Consequently, energy consumption caused by the urban development should also be considered as one of the main factors affecting the environemnt.

From the analysis of these data it follows that in modern cities the main consumer of fuel and energy resources is transport, the use of which increases the amount of emissions of harmful substances into the environment.

On the other hand, the energy consumed by civil buildings exceeds the energy consumption of the entire industry with all plants, factories and the energy consumption of all modes of transport. Fig. 2 shows the distribution of energy consumption in Europe. [6]

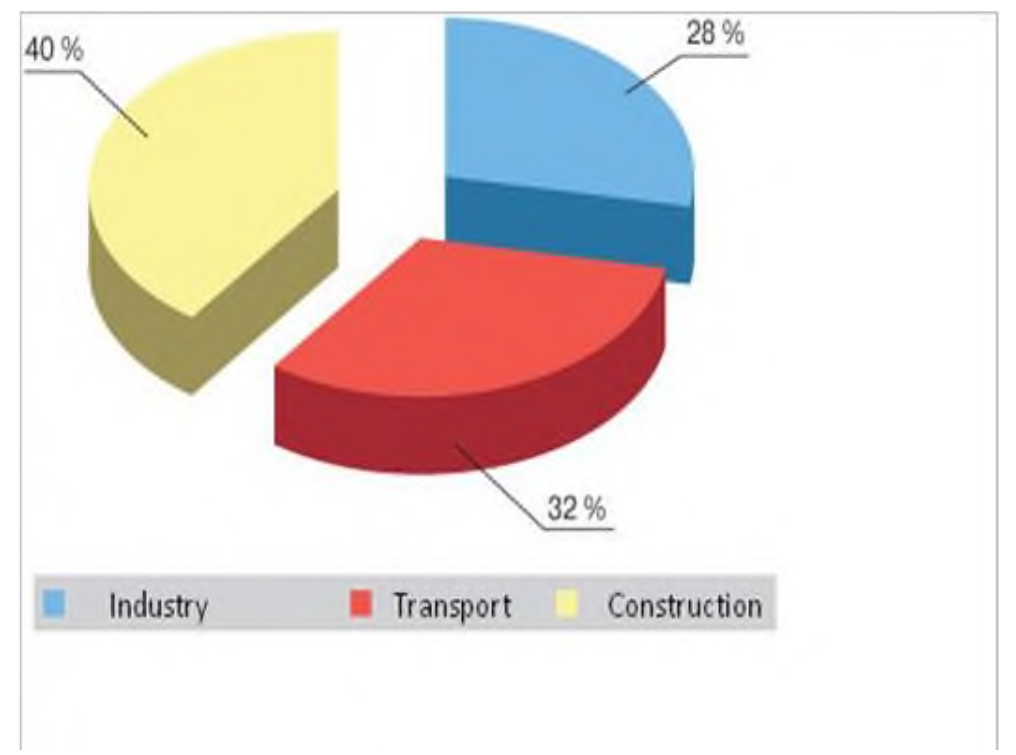

Fig. 3. Consumption of energy by industry

Therefore, it can be argued that the growth of residential construction, and in the future, the operation of residential facilities will adversely affect the urban environement. 


\section{Materials and Methods}

The central part of Russia and the north-western region and the cities of Primorsky Krai are becoming leaders in terms of construction volumes. The analysis of the city of Vladivostok in the Primorsky Krai revealed that the urban environemnt is unfavorable. According to Rosstat, in August the housing construction sector in the city of Vladivostok showed an increase of $14.7 \%$ compared to that of July 2020 . It is obvious that such a growth rate of construction leads to the environmental degradation in these regions.

The city of Vladivostok is a large industrial city and port in the Far East of Russia and is similar to St. Petersburg in terms of its climate. In Vladivostok, there are 25 enterprises with 1239 sources of emissions of pollutants of 1-4 hazard classes. The atmospheric air in Vladivostok is most polluted by benzpyrene and nitrogen dioxide. The average annual concentration of benzpyrene exceeds the permissible norm by 3 times, which corresponds to a high level of pollution; concentration of nitrogen dioxide exceeds by 1.5 times.

Moreover, Vladivostok, like any other modern city, is characterized by an increase in the number of cars and the development of transport networks. It also leads to an increase in the level of urban pollution. Over the past decades, the share of emissions from cars and trucks has increased significantly. In large cities, vehicles account for 30 to $70 \%$ of total emissions. In general, motor transport produces more than 40 chemical substances into the air of Vladivostok, and each of them is harmful to the human body to varying degrees. The main ingredients include carbon monoxide (up to $70 \%$ ), carcinogenic polycyclic aromatic hydrocarbons (about 19\%) and nitrogen oxides (about 9\%). Combustion of 1 ton of fuel by a gasoline car engine leads to the formation of an average of $600 \mathrm{~kg}$ of carbon monoxide. Unlike gasoline engines, diesel engines emit significantly more smoke, which consists mainly of unburned carbon. In addition, the operation of internal combustion engines is accompanied by emissions of heavy metal compounds into the atmosphere. First of all, it is lead formed when using leaded gasoline.

Thus, it can be argued that the main factors that negatively affect the environment of Vladivostok are the rapid growth of modern urban construction, an increase in population density and an increase in the amount of transport.

The process of urban development contributes to a change in the spatial planning of territories, causing a rapid increase in the number of roads and traffic density of road transport. As a result of an increased the density of buildings, the natural aeration of the territory is disrupted and vast and stable zones with the most unfavorable indicators of atmospheric air are formed in the air basin of a modern city. Such zones include areas with a radial-circular arrangement of streets and closed courtyards of cities. A significant increase in the level of air pollution is facilitated by air stagnation in residential areas, which arise as a result of surface temperature inversion and calm, when wind speeds are from 0 to $1 \mathrm{~m} / \mathrm{s}$ [7-8].

The disrupted natural wind conditions in the courtyard space of a modern city, caused by dense high-rise buildings, contributes to the concentration of pollutants due to the lack of the necessary air exchange. One of the solutions to the problem of improving the environment of the urban air basin is to ensure the necessary air exchange in courtyard spaces.

Air exchange of closed courtyard spaces, where natural aeration is disrupted, largely depends on the wind speed increasing along the elevation of the building facades. The city of Vladivostok, like other modern cities, is characterized by high-rise buildings. Near the facade of a high-rise building, the speed of the wind usually increases when it goes up, and in summer, convective flows increase at the facades irradiated by the sun. As a result, powerful turbulent flows arise at the facades, depending on the shape of the building, the terrain, surrounding buildings and other factors. The study of the aerodynamic conditions of 
urban areas can help solve the problem of the concentration of pollutants on the active surface of a closed urban space [9].

\section{Results}

To assess the aerodynamic conditions for the development of the urban space of Vladivostok, the calculation of the change in the wind speed along the height of the building was carried out, using the example of the Evolution Tower in Moscow. The climatic parameters of the city of Vladivostok were used for the calculation.

To determine changes in wind speed with respect to altitude, various models are used the Ekman's spiral, the logarithmic law, and the power law [10,11] These models allow measuring wind speed $V$ at altitude $h$ if the wind speed $V_{0}$ at altitude $h_{0}$ is known.

The power law of variation of wind speed with changes in altitude has the form:

$$
V_{h}=V_{0}\left(h / h_{0}\right)^{a} \mathrm{~m} / \mathrm{s}
$$

where $V_{h}$ is wind speed, $\mathrm{m} / \mathrm{s}$, at altitude высоте $\mathrm{h}, \mathrm{m}$;

$V_{0}$ is wind speed, $\mathrm{m} / \mathrm{s}$, measured at altitude $h_{0}, \mathrm{n}$ (wind sppeds are measured at altitudes $10-15 \mathrm{~m}$, therefore $\left.h_{0}=10-15 \mathrm{~m}\right)$;

$\alpha$ is exponent, depending on the type of terrain and established experimentally; it is recommended for the centers of large cities to take $\alpha=0.33$, for suburbs $\alpha=0.22$, for open areas $\alpha=0.14$ [6].

Based on the results of the calculation, a graph of the dependence of the wind speed on the height of the building was plotted, taking into account the type of terrain (Fig. 4).

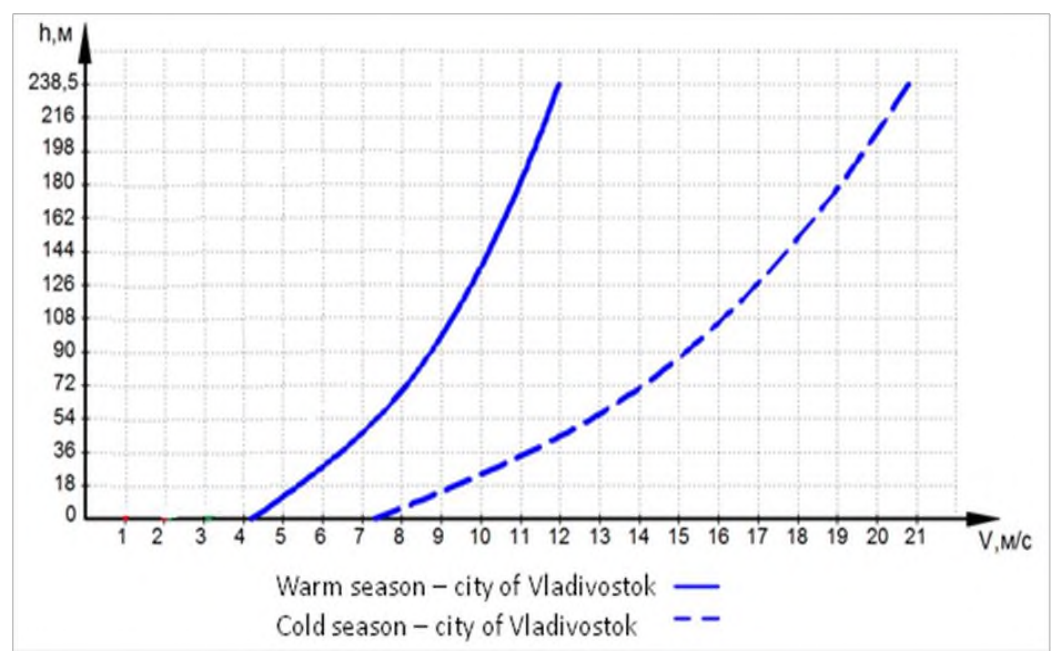

Fig. 4. Changes in height of the Evolution Tower for wind speed in Vladivostok

As can be seen from this graph, the wind speed increases with the height of the building. In addition, during the warm period of the year, the temperature of the outer surfaces of the building rises sharply due to exposure to solar radiation and differs significantly from the outside air temperature. In confined spaces, due to the temperature difference between the irradiated and shaded facades of buildings, ascending convective 
currents of thermal origin appear in the courtyard space. The speed of such currents can reach $10 \mathrm{~m} / \mathrm{s}$, depending on the height.

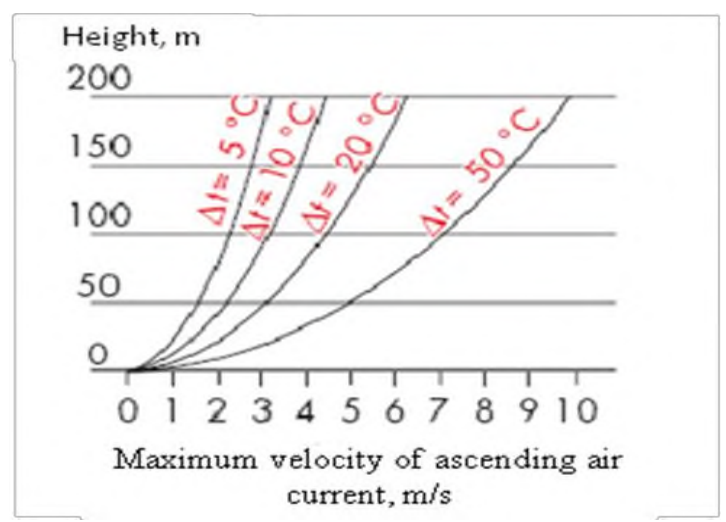

Fig. 5. The dependence of the speed of ascending flows on the height

The amount of solar radiation and the absorption coefficient of solar radiation by the material of the outer surface of walls creates a temperature difference between the outer surface of the building and the ambient air. The temperature difference contributes to the formation of a convective heat flow directed upward of the building (Fig. 5) [12]. In a closed urban space with modern high-rise buildings, heat-wind disturbances of thermal origin are formed. Consequently, territories of a modern city must be considered as those with difficult aerodynamic conditions. The analysis and assessment of these aerodynamic factors will make it possible to find ways to eliminate the concentration of pollutants in closed unventilated living spaces [13-15].

Therefore, when designing high-rise buildings, it is necessary to take into account not only the aerodynamic characteristics of the terrain, but also convective flows that are formed as a result of temperature differences.

\section{Conclusions}

Based on the studies carried out, it can be argued that to ensure the stability of the urban environment, it is necessary to consider the following.

- Competent planning of urban space and transport networks contributes to reduction in road congestion causing inefficient consumption of fuel and energy resources by transport.

- When planning an urban area, it is necessary to take into account the peculiarities of the built-up areas, the volumetric-spatial plasticity and the density of future buildings, affecting the aerodynamics of the area and air pollution.

- In closed urban areas where there is no sufficient ventilation, it is necessary to provide aeration by regulating convective flows of thermal origin. Competent arrangement of buildings and landscaping of territories at the design stage will solve this problem.

\section{References}

1. J. K. Niemelä, Landscape and Urban Planning, 125(5), 298-303 (2014)

2. H. Jeong, M. Park, W. Hwang, E. Kim, M. Han, Annals of Nuclear Energy, 55(5) 230237 (2013) 
3. Y. A. Tabunshchikov, N. V. Shilkin, AVOK 8 (2004)

4. S. Paiho, I. P. Seppa, C. Jimenez Sustainable Cities and Society, 15(7), 75-79 (2015) https://doi.org/10.1016/j.scs.2014.12.005

5. I. A. Bashmakov, Energosberezhenie, 1, 62-67 (2010)

6. B. M. Shojhet, Ehnergosberezhenie, 7, 62-66 (2007)

7. H. Jeong, M. Park, W. Hwang, K. Kim, M. Han, Annals of Nuclear Energy, 55, 230237 (2013)

8. Q. Wang, Y. Wang, Y. Fan, J. Hang, Y. Li, Building and Environment, 148, 433-447 (2019)

9. V. L. Kashintseva, D. A. Leonova, T. B. Giyasov, Byulleten' stroitel'noy tekhniki, 12, 27-30 (2018)

10. A. N. Kolubkov, AVOK, 4 (2005)

11. A. N. Kolubkov, N. V. Shilkin, AVOK, 5 (2004)

12. O. D. Samarin, Zhilishchnoye stroitel'stvo, 1, 32 - 33 (2013)

13. A. Giyasov, Y. G. Barotov, Ekologiya urbanizirovannykh territoriy 3 90-97 (2018)

14. B. I. Giyasov, Vestnik MGSU, 4, 17-21 (2012)

15. Kh. Karimov, A. Kh. Khakim, M. Abid, G. Petrov, Science of The Total Environment, 461, 835-838 (2013) 